\title{
Influence of Heat Exchanger Design on the Thermal Performance of a Domestic Wine Cooler Driven by a Magnetic Refrigeration System
}

\author{
GUILHERME F. PEIXER, SERGIO L. DUTRA, RICARDO S. CALOMENO, \\ NATÁLIA M. DE SÁ, GUSTTAV B. LANG, JAIME A. LOZANO \& JADER R. BARBOSA JR
}

\begin{abstract}
Conventional and not-in-kind refrigerators require heat exchangers for their operation. Yet, most magnetic cooling studies do not take full account of those components despite their importance in defining the cooling capacity and temperature span. To investigate the influence of heat exchanger design parameters on the performance of magnetic refrigerators, a model was developed to integrate the heat exchangers, regenerators and thermal reservoirs. The results were compared with data generated in an apparatus that emulates the conditions of the thermal fluid supplied by the regenerators to a cold heat exchanger positioned inside the cabinet of a retrofitted 130-liter wine cooler. Six tube-fin heat exchangers were evaluated to identify the most suitable geometry (number of tube rows and fin density) for the compact magnetic refrigerator. Numerical simulations described the influence of the heat exchanger on the regenerator performance in terms of the liquid stream effectiveness. For a temperature span of $20^{\circ} \mathrm{C}$ between the external environment and the refrigerated compartment, the best heat exchanger/fan assembly resulted in a cooling capacity reduction of $37 \%$ and a temperature span increase of $32 \%$, in comparison with an idealized system. The expected system coefficient of performance (COP) and second-law efficiency were $1.8 \%$ and $13 \%$, respectively.
\end{abstract}

Key words: Magnetic refrigeration, active magnetic regenerator, heat exchanger, integrated design, wine cooler cabinet.

\section{INTRODUCTION}

Magnetic refrigeration stands out as one of the most promising not-in-kind cooling technologies. It is based on the magnetocaloric effect (MCE), which is defined as the thermal response of a magnetic material when subjected to a variation in the applied magnetic field. Because of the small magnitude of the MCE - typically $3^{\circ} \mathrm{CT}^{-1}$ for commercial-grade gadolinium (Gd) (Gschneidner \& Pecharsky 2008) - thermal regenerative cycles are usually employed in magnetic refrigeration systems. The active magnetic regenerator (AMR) (Barclay \& Steyert 1982) consists of a porous structure composed of one or more layers of magnetocaloric material crossed periodically by a thermal fluid. In this configuration, the fluid is used to promote heat transfer between the solid matrix and the thermal reservoirs, causing the magnetocaloric material to operate both as regenerative matrix and refrigerant.

Due to the reversibility of the MCE in some types of materials and the use of regenerative thermodynamic cycles, magnetic refrigerators have the potential to develop high efficiencies. The 
absence of harmful gases and high pressures is also seen as an advantage compared to some cooling and heat pumping applications (e.g., air conditioning). Nevertheless, several challenges still prevent magnetic refrigerators from becoming commercially available, particularly those associated with cost (mainly of magnetocaloric materials and the magnetic circuits) and mechanical losses in ancillary systems, such as the hydraulic circuit (Yu et al. 2010, Kitanovski et al. 2015, Trevizoli et al. 2016a, Greco et al. 2019).

Heat exchangers are responsible for a substantial share of the overall losses in refrigerators and heat pumps. The efficiency breakdown of a domestic refrigerator performed by Gonçalves et al. (2011) indicated that the heat exchangers are the major source of irreversibility in household and light commercial applications. In their exergetic evaluation of vapor compression refrigerators, Morosuk \& Tsatsaronis (2009) concluded that the evaporator should be the first component to be upgraded for the benefit of improving the overall system performance. Analogously, through an exergy destruction analysis, Arora \& Kaushik (2008) found that the major sources of irreversibility are located in the condenser.

Even though the importance of the heat exchangers to the overall performance of conventional cooling systems has been widely explored and documented in the literature (Klein \& Reindl 1998, Gholap \& Khan 2007, Waltrich et al. 2011), to date, most magnetic cooling prototypes used Joule-effect heaters in contact with the heat transfer fluid on the cold side to generate the thermal load (Kitanovski et al. 2015). Despite the convenience of this technique, it is clearly not capable of fully reproducing the real thermal interaction between the cooling system and the refrigerated environment. In actual magnetic cooling systems, heat exchangers will have finite overall thermal conductances which will affect the operating conditions of the AMR and the thermodynamic performance of the device (Trevizoli et al. 2016a).

According to Bjфrk et al. (2016), one of the fundamental requirements for a magnetocaloric system to perform efficiently is to have a temperature difference with respect to the source $/$ sink of around $2^{\circ} \mathrm{C}$. In contrast, heat exchangers in vapor compression systems operate with temperature differences of the order of $10^{\circ} \mathrm{C}$. For low temperature differences (typically $2-5 \mathrm{~K}$ ) to be achieved, forced convection and large heat transfer surface areas are needed. In addition to the increase in material cost and power consumption, forced convection heat exchangers also generate an extra heat load due to the heat dissipation caused by the cold fan, demanding higher cooling capacities. Engelbrecht (2004) and Calomeno et al. (2016) used the $\varepsilon$-NTU method (Kays \& London 1984) to demonstrate that the performance of AMRs is extremely sensitive to reductions in the overall thermal conductance of the hot and cold heat exchangers. Chaudron et al. (2014) evaluated, in an AMR system equipped with real heat exchangers, the effect of the operating condition on the cooling capacity and temperature difference in the cold heat exchanger. They concluded that (i) the heat exchanger design should take into account the pressure drop and thermal effectiveness trade-off and (ii) the coupling of these components provides optimal operating points for a magnetic refrigeration system. Hittinger et al. (2016) demonstrated the influence of the heat exchangers and fans on the performance of a magnetic refrigeration system. By redesigning the heat exchanger, the authors obtained lower cabinet temperatures and higher cooling rates, confirming that these components are key items to be considered on the design of magnetic refrigeration systems. 
The refrigerated cabinet, another fundamental component of cooling devices, has not been considered or evaluated in the open literature as regards the performance of magnetic refrigerators. Thermodynamically speaking, the insulated cabinet links the cooling capacity to the temperature span, defining the operating point of the cooling device. Moreover, the power consumption of a refrigeration system is dictated principally by the heat load through the cabinet walls (Melo et al. 2000), thus making the evaluation of this component fundamental to the design of magnetic refrigerators.

The few attempts to analyze the impact of the heat exchangers on the performance of magnetic refrigerators (Engelbrecht 2004, Calomeno et al. 2016) were based on numerical simulations in which the heat exchanger effectiveness was an input parameter (for both the hot and cold sides). Thus, an integrated model in which the geometric characteristics of the heat exchangers and the operating conditions of the cooling system are the input parameters is essential to develop an efficient and compact magnetic refrigerator capable of operating between the temperatures specified for the hot and cold environments.

Through a combination of mathematical modeling and experiments, the present paper evaluates the influence of the geometric characteristics of fin-tube heat exchangers (namely the number of tube rows and fin density) on the performance of a magnetic refrigeration system. A domestic wine cooler has been selected as the target application. Detailed temperature and cooling capacity measurements were carried out in a retrofitted wine refrigerator cabinet connected to an experimental apparatus that emulated the behavior of the temperature and flow rate of the heat transfer fluid supplied by the AMR to the hot and cold heat exchangers integrated in the cabinet structure. A mathematical model based on the $\varepsilon$-NTU method, which incorporates the fluid flow characteristics and heat exchanger geometry parameters, was developed to thermally integrate the cabinet and the AMR. The latter was simulated using an experimentally validated 1-D AMR model (Trevizoli et al. 2016b). The analysis enabled the identification of the heat exchanger geometry which resulted in the lowest power consumption of the AMR/refrigerator cabinet assembly.

\section{EXPERIMENTAL WORK}

\section{Experimental facility: the AMR emulator}

The experimental apparatus consists of two similar hydraulic circuits, the hot and cold loops, which are responsible for emulating the temperature and flow rate of the fluid flow streams produced by a hypothetical AMR during the cold and hot blows, respectively. The circuits, shown schematically in Fig. 1, are integrated with the cabinet of the wine cooler by the cold and hot tube-fin heat exchangers. Fig. 2 shows a photograph of the apparatus connected to the wine cooler cabinet.

Each hydraulic circuit is composed of a rotary vane pump powered by an electric motor to provide continuous changes of the mass flow rate in each circuit. The thermal fluid is a $20 \%$ vol. solution of automotive antifreeze (ethylene glycol with corrosion inhibitors) in deionized water. The operating frequency of the pumps are controlled by frequency inverters, while needle valves help to regulate the mass flow rate through the circuits. Check valves guarantee unidirectional fluid flow in the by-pass lines.

Using the cold circuit as an example, the temperature of the fluid entering the cold heat exchanger (CHEx), which corresponds to the temperature of the fluid exiting the AMR in the hot blow, is set by an 


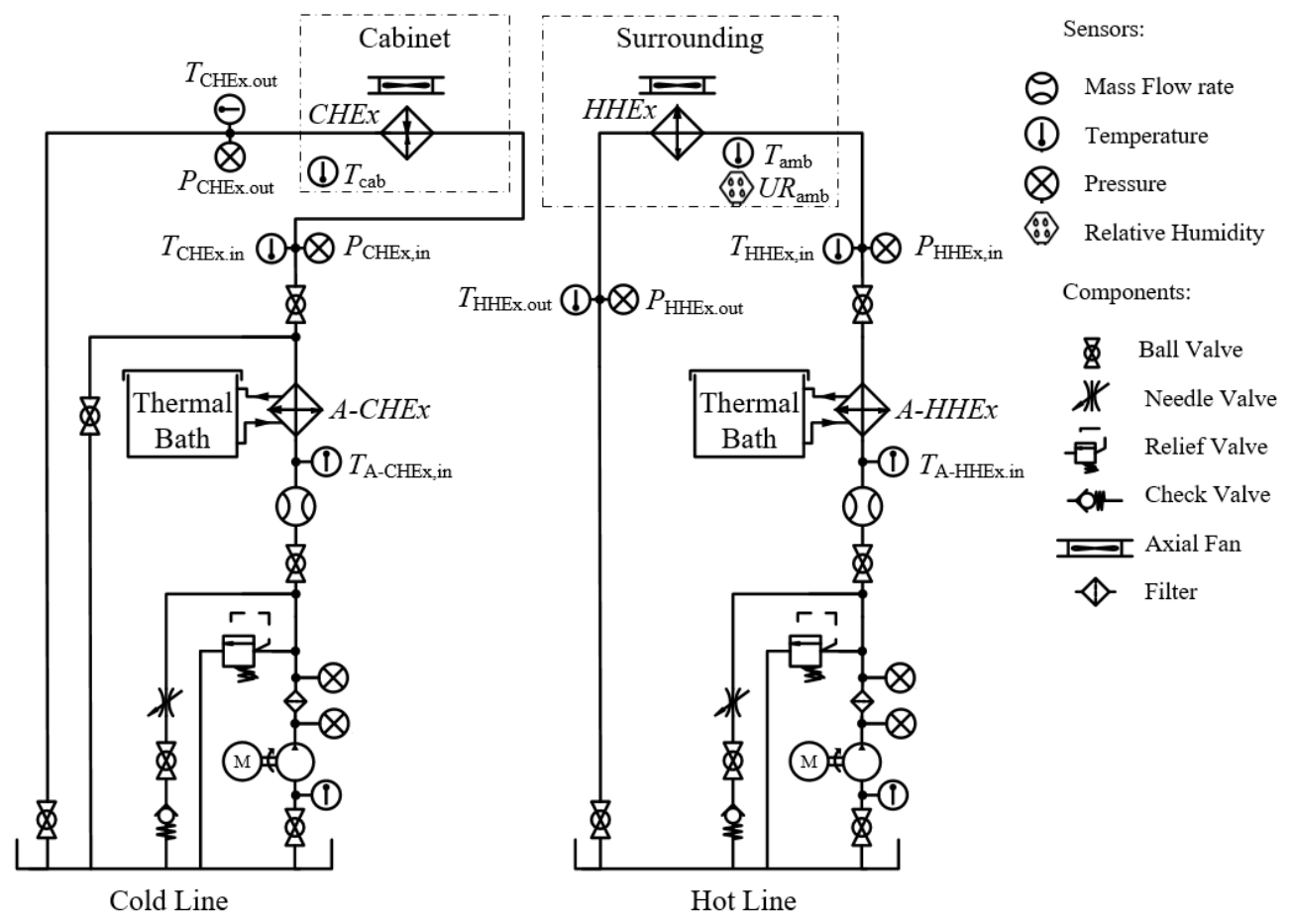

Figure 1. Schematic diagram of the experimental apparatus (AMR emulator).

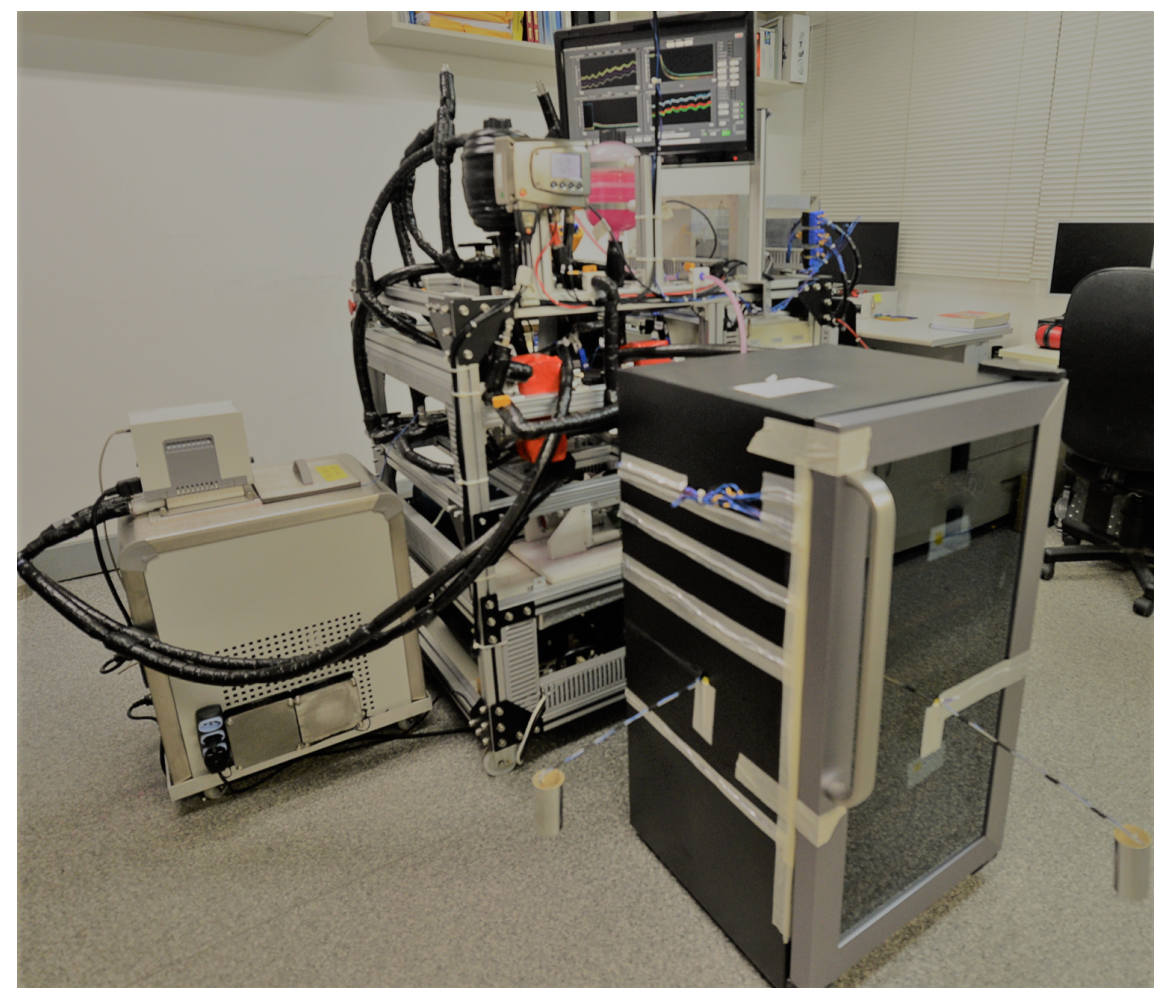

Figure 2. Retrofitted wine cooler cabinet connected to the experimental apparatus. 
auxiliary brazed-plate heat exchanger (AHEx) connected to a temperature controlled bath. An axial fan (see Section Heat exchanger samples) powered by an external source drives the cabinet air through the tubes and the fins of the CHEx. The air flow rate (at the operating point) is determined by matching the fan static pressure curve and the CHEx pressure drop curve. A similar setup was implemented in the hot circuit.

As shown in Fig. 1, each circuit of the AMR emulator was equipped with four pressure transducers (Omega PX309-300 psia, expanded uncertainty of 0.05 bar), calibrated thermocouples (Omega TMQSS-062G-6, expanded uncertainty of $0.2 \mathrm{~K}$ ) and a Coriolis flow transducer (Siemens MASS 2100 $\mathrm{DI}$, expanded uncertainty of $0.02 \mathrm{~kg} \mathrm{~h}^{-1}$ ). The relative humidity of the external ambient was measured with a humidity transducer (Testo 6681, expanded uncertainty of $0.15 \%$ relative humidity). The ambient temperature was controlled by an air conditioner equipped with a variable-speed compressor (expanded uncertainty of $1 \mathrm{~K}$ ).

\section{Wine cooler cabinet}

As shown in Fig. 2, a commercially available 130-l (31-bottle) wine cooler cabinet has been used in this study. Before removing the original vapor compression refrigeration system (compressor, roll-bond evaporators, wire-on-tube condenser and capillary tubes), power consumption and temperature pull-down tests have been carried out in a climatic chamber according to the methodology proposed by Hermes et al. (2013) to serve as a baseline for future comparisons with real AMR systems.

The overall thermal conductance of the wine cooler cabinet, which includes losses through the foam insulation, magnetic gaskets and glass door, has been determined experimentally via the reverse heat loss rate test (Melo et al. 2000). In such tests, several electric heaters are distributed within the unplugged refrigerator cabinet and, by measuring the power supplied to the heaters and the temperature at multiple measuring stations inside and outside the refrigerated compartments, the following energy balance can be written:

$$
(U A)_{\text {top }}\left(\bar{T}_{\text {top }}-\bar{T}_{\text {amb }}\right)+(U A)_{\text {bot }}\left(\bar{T}_{\text {bot }}-\bar{T}_{\text {amb }}\right)=\overline{\dot{W}}_{\text {top }}+\overline{\dot{W}}_{\text {bot }}
$$

where $\bar{T}_{\text {top }}, \bar{T}_{\text {bot }}$ and $\bar{T}_{\text {amb }}$ are space and time average temperatures of the air inside the top and bottom compartments of the original (i.e., pre-retrofitting) cabinet and the surrounding ambient air, respectively.

Four independent reverse heat leakage tests have been performed in the climatic chamber, resulting in the following values of the overall thermal conductances via linear regression: (UA) top $=$ $1.09 \mathrm{~W} \mathrm{~K}^{-1},(U A)_{\text {bot }}=0.69 \mathrm{~W} \mathrm{~K}^{-1}$. The cabinet overall thermal conductance, $(U A)_{\text {cab }}$, given by the sum of the conductances of the top and bottom compartments, was equal to $1.78 \mathrm{~W} \mathrm{~K}^{-1}$. It is assumed that $(U A)_{\text {cab }}$ remained unchanged after retrofitting the original refrigerator cabinet.

The location of the three thermocouples used for measuring the internal air temperature during the wine cooler performance tests (after retrofitting) are shown in Fig. 3 together with the position of the cold heat exchanger/fan assembly and some internal cabinet dimensions. The mean surrounding ambient temperature, $\bar{T}_{\mathrm{amb}}$, is computed from three thermocouples placed around the cabinet (two of them are visible in Fig. 2, sticking out of the glass door and side wall). 


\section{Heat exchanger samples}

The cold heat exchanger of the original refrigeration system was a natural draft roll-bond evaporator, which typically operates with a temperature driving potential higher than $10^{\circ} \mathrm{C}$ in vapor compression systems. For the operation of magnetic cooling devices it would be more advantageous to work with smaller temperature spans, due to the high magnetization power consumption associated with larger spans, as will be discussed later. Therefore, compact herringbone wave-type tube-fin heat exchangers have been selected for the present analysis. Fig. 3 presents the geometric configuration and main design parameters of a typical heat exchanger of such configuration.

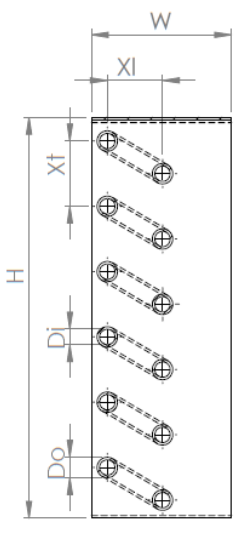

SECTION J-J
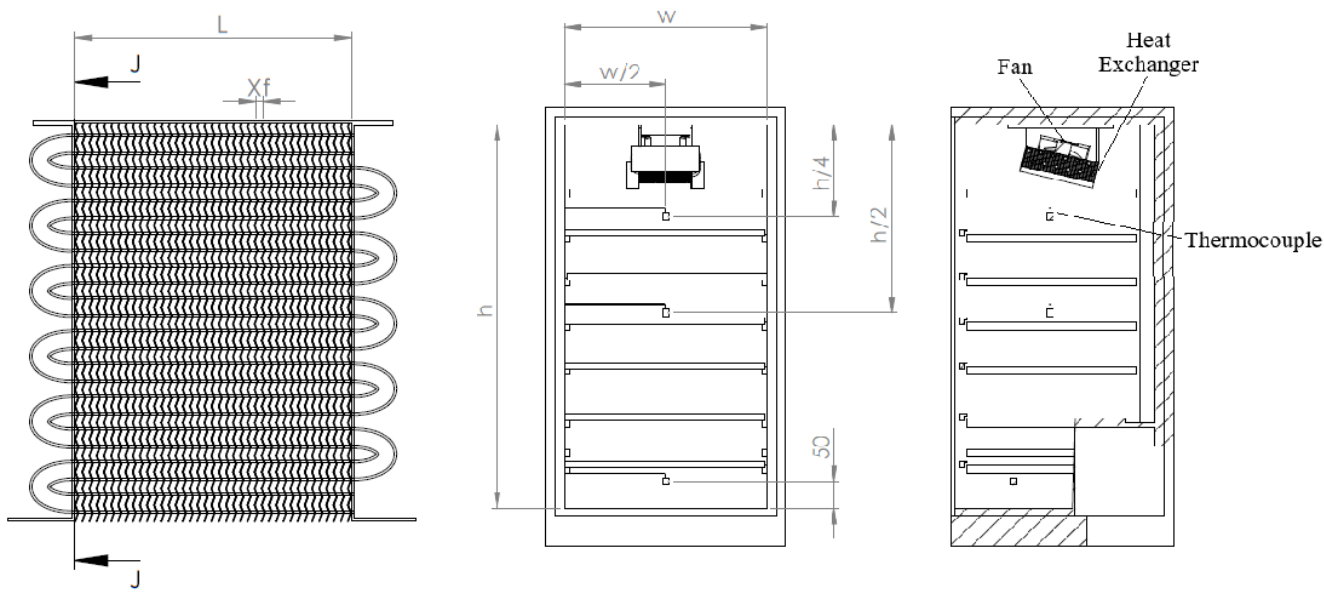

Figure 3. Schematic representation of a two-row wavy-type tube-fin heat exchangers and cabinet air temperature measurement locations and cold heat exchanger position inside the wine cooler cabinet. The heat exchanger dimensions are defined in Table I. The cabinet dimensions are $w=42 \mathrm{~mm}, h=83 \mathrm{~mm}$.

A Bi-Sonic 433-BP 1202512 fan (capable of operating at three different speeds, with three distinct head curves) was selected to drive the air through the tube-fin heat exchanger and, in the experiments performed, the fan speed was kept fixed at its maximum value.

Given the fixed diameter of the fan and due to manufacturing limitations, the frontal area of the heat exchanger was kept fixed in the analysis, as well as the longitudinal and transversal tube pitches, and the inner and outer diameters of the tubes. These parameters are summarized in Table I.

Table I. Summary of the fixed geometric parameters common to all heat exchanger samples.

\begin{tabular}{|c|c|c|}
\hline Parameter & Symbol & Value \\
\hline Heat exchanger length $[\mathrm{mm}]$ & $\mathrm{L}$ & 110 \\
Heat exchanger height $[\mathrm{mm}]$ & $H$ & 152 \\
Longitudinal tube pitch $[\mathrm{mm}]$ & $X_{\mathrm{l}}$ & 21.5 \\
Transversal tube pitch $[\mathrm{mm}]$ & $X_{\mathrm{t}}$ & 25.4 \\
Inner tube diameter $[\mathrm{mm}]$ & $D_{\mathrm{i}}$ & 6.5 \\
Outer tube diameter $[\mathrm{mm}]$ & $D_{\mathrm{o}}$ & 7.5 \\
\hline
\end{tabular}


Due to volume constraints inside the cooler cabinet, a maximum of two tube rows was allowed in the cold heat exchanger. Thus, the number of rows, fin density and the air volumetric flow rate are the main independent variables in the heat transfer and pumping power analysis. Hence, three different fin densities and two different row number configurations were evaluated, as summarized in Table II.

Table II. Summary of the variable geometric parameters of the heat exchanger samples.

\begin{tabular}{|c|c|c|}
\hline HEX & Number of rows, $N_{\mathrm{r}}$ & Fin density, $\varsigma$ \\
\hline 1 & 1 & 300 \\
2 & 1 & 400 \\
3 & 1 & 500 \\
4 & 2 & 300 \\
5 & 2 & 400 \\
6 & 2 & 500 \\
\hline
\end{tabular}

\section{Experimental procedure}

The experimental apparatus (comprising the AMR emulator, wine cooler cabinet and heat exchangers) was subjected to steady-state and transient tests to determine important wine cooler operating parameters, such as the cabinet equilibrium temperatures, thermal load and the time required to reach thermal equilibrium (temperature pull down). While the transient analysis will be the focus of another paper, the present analysis is dedicated to validating the system thermal behavior at steady state, emphasizing the impact of the heat exchangers on the system performance.

The experimental procedure for the steady-state tests consists of the following steps: (i) the pumps of the cold and hot circuits are switched on and the desired temperatures of the hot and cold thermal fluids are set in their respective thermal baths; (ii) the mass flow rates in each circuit are adjusted using the needle valves, while the desired ambient temperature is controlled by the room air conditioner.

When the desired test condition is reached, the steady-state criterion is checked, which consists of having the standard deviations of key temperature readings stabilized within their expanded uncertainties for 25 continuous minutes. The data are recorded at a rate of $1 \mathrm{kHz}$ for 5 minutes.

The main performance parameters derived from the experimental data are the average cabinet air temperature, $\bar{T}_{\text {cab }}$, the system temperature span, the cooling capacity (obtained from a fluid-side energy balance on the cold heat exchanger) and the cabinet thermal load, given respectively by:

$$
\begin{gathered}
\Delta T_{\text {span }}=\bar{T}_{\mathrm{amb}}-\bar{T}_{\mathrm{cab}} \\
\dot{\mathrm{Q}}_{\mathrm{c}}=\dot{m}_{\mathrm{l}} C_{\mathrm{p}, \mathrm{l}}\left(T_{\mathrm{l}, \mathrm{c}, \mathrm{out}}-T_{\mathrm{l}, \mathrm{c}, \mathrm{in}}\right) \\
\dot{\mathrm{Q}}_{\mathrm{cab}}=(U A)_{\mathrm{cab}} \Delta T_{\mathrm{span}}
\end{gathered}
$$

where $\bar{T}_{\text {cab }}$ is obtained through an average of three thermocouples placed inside the cabinet, as presented in Fig. 3. For a target system temperature span of $20 \mathrm{~K}$, and since $(U A)_{\text {cab }}$ is $1.78 \mathrm{~W} \mathrm{~K}^{-1}$, 
the cabinet thermal load was calculated as $35.6 \mathrm{~W}$. The expanded uncertainties associated with the experimentally determined parameters are presented in Table III.

Table III. Summary of the experimental uncertainties ( $95 \%$ confidence interval) of the variables associated with the determination of the cabinet thermal load.

\begin{tabular}{|c|c|}
\hline Variable & Uncertainty \\
\hline $\bar{T}_{\text {amb }}$ & $0.12^{\circ} \mathrm{C}$ \\
$\bar{T}_{\text {cab }}$ & $0.1^{\circ} \mathrm{C}$ \\
$\Delta T_{\text {span }}$ & $0.16^{\circ} \mathrm{C}$ \\
$(U A)_{\text {cab }}$ & $0.08 \mathrm{~W} \mathrm{~K}^{-1}$ \\
$\dot{Q}_{\text {cab }}$ & $3 \mathrm{~W}$ \\
\hline
\end{tabular}

\section{Test conditions}

Preliminary tests indicated that the liquid mass flow rate in the cold circuit, normally held between 40 and $150 \mathrm{~kg} \mathrm{~h}^{-1}$, had little influence on the final temperature of the cabinet. Thus, the inlet temperature of the liquid in the cold heat exchanger, $T_{l, c, \text { in }}$, was the main independent parameter in the present analysis. Other parameters held fixed during the experiments were the ambient temperature and the relative humidity of the ambient air, as shown in Table IV. For each heat exchanger sample, seven tests were carried out in which $T_{1, c, \text { in }}$ was varied from $5^{\circ} \mathrm{C}$ (Test No. 1) to $-5^{\circ} \mathrm{C}$ (Test No. 7).

Table IV. Independent parameters kept fixed during the experimental campaign.

\begin{tabular}{|l|c|}
\hline Parameter & Admissible values \\
\hline Ambient temperature $\left(T_{\mathrm{amb}}\right),{ }^{\circ} \mathrm{C}$ & $25 \pm 1$ \\
Relative humidity, $\%$ & $55 \pm 15$ \\
Cold liquid mass flow rate $\left(\dot{m}_{\mathrm{c}, 1}\right), \mathrm{kg} \mathrm{h}^{-1}$ & $150 \pm 1$ \\
\hline
\end{tabular}

Experiments without and with a hot heat exchanger (HHEx) in place (also a tube-fin heat exchanger of similar characteristics, positioned in the space previously occupied by the compressor) showed that the influence of the latter on the cabinet air temperature was negligible for an inlet temperature of the liquid of $40^{\circ} \mathrm{C}$ in the HHEx. A similar conclusion was reached regarding the presence of wine bottles filled with water during the tests at steady-state. Nevertheless, as discussed in Calomeno (2018), the temperature pull down (i.e., transient) tests were significantly affected by the thermal capacity of the bottles.

Additionally, each test for heat exchanger Sample 5 was repeated twice by two different operators to eliminate their influence on the experimental results. 


\section{MATHEMATICAL MODELS}

Several sub-models have been implemented to describe the different components and sub-systems of the wine cooler. Fig. 4 illustrates the interconnection between them.

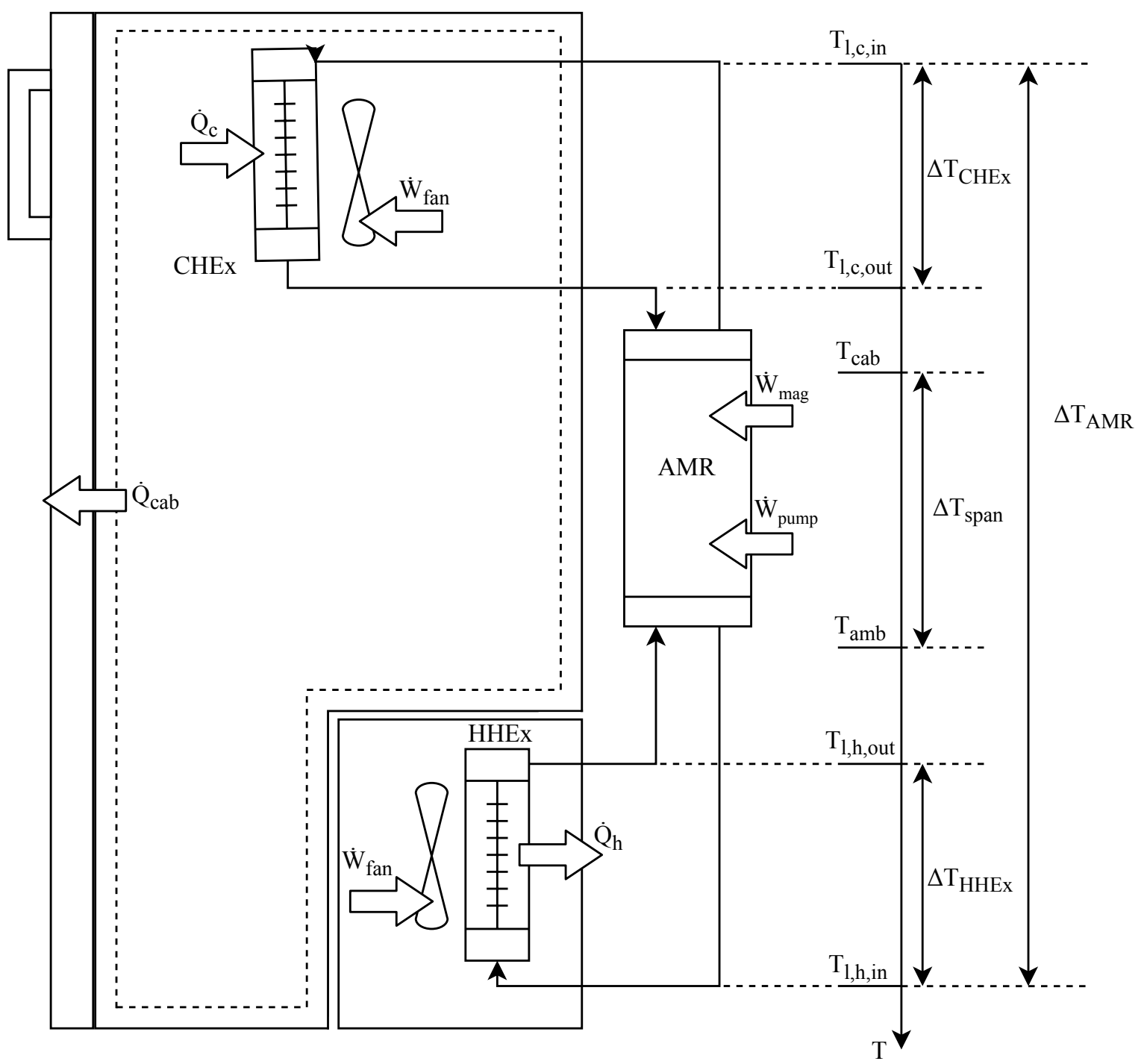

Figure 4. Schematic diagram of the mathematical models identifying the sub-systems of the experimental apparatus.

\section{Cabinet and heat exchanger model}

The thermal reservoirs (i.e., the cabinet air and the ambient air) and the AMR are interconnected by the cold and hot heat exchangers, which were modelled via the $\varepsilon$-NTU method (Kays \& London 1984). It is important to mention that one way to apply the model presented in this section is to use it independently from the models the that describe the thermal performance of the AMR, meaning 
that its input parameters, for example, $T_{l, c, \text { in }}, T_{l, h, \text { in }}, T_{l, c, \text { out }}, T_{l, h \text {,out }}$ can be obtained directly from experiments performed in the AMR emulator described in Section Experimental facility: The AMR emulator.

In each heat exchanger, by equating the liquid-side enthalpy change to the definition of the heat transfer rate in terms of the heat exchanger effectiveness, one has:

$$
\begin{gathered}
\dot{Q}_{\mathrm{c}}=\dot{C}_{\mathrm{l}, \mathrm{c}}\left(T_{\mathrm{l}, \mathrm{c}, \text { out }}-T_{\mathrm{l}, \mathrm{c}, \mathrm{in}}\right)=\varepsilon_{\mathrm{c}} \dot{C}_{\text {min }, \mathrm{c}}\left(T_{\mathrm{a}, \mathrm{c}, \mathrm{in}}-T_{\mathrm{l}, \mathrm{c}, \mathrm{in}}\right) \\
\dot{Q}_{\mathrm{h}}=\dot{C}_{\mathrm{l}, \mathrm{h}}\left(T_{\mathrm{l}, \mathrm{h}, \text { out }}-T_{\mathrm{l}, \mathrm{h}, \mathrm{in}}\right)=\varepsilon_{\mathrm{h}} \dot{C}_{\min , \mathrm{h}}\left(T_{\mathrm{l}, \mathrm{h}, \mathrm{in}}-T_{\mathrm{a}, \mathrm{h}, \mathrm{in}}\right)
\end{gathered}
$$

where $\dot{C}$ is the heat capacity of the stream, $\dot{C}=\dot{m} c_{p}$, and $\varepsilon$ and $\dot{C}_{\text {min }}$ for the hot and cold heat exchangers are obtained through a thermal-hydraulic model described in detail below. For all cases evaluated in this study, the minimum heat capacity rates were those associated with the air streams in both the cold and hot heat exchangers. Analogously, the overall energy balances give:

$$
\begin{gathered}
\dot{Q}_{\mathrm{c}}=\dot{C}_{\mathrm{l}, \mathrm{c}}\left(T_{\mathrm{l}, \mathrm{c}, \text { out }}-T_{\mathrm{l}, \mathrm{c}, \mathrm{in}}\right)=\dot{C}_{\mathrm{a}, \mathrm{c}}\left(T_{\mathrm{a}, \mathrm{c}, \text { in }}-T_{\mathrm{a}, \mathrm{c}, \text { out }}\right) \\
\dot{Q}_{\mathrm{h}}=\dot{C}_{\mathrm{l}, \mathrm{h}}\left(T_{\mathrm{l}, \mathrm{h}, \text { out }}-T_{\mathrm{l}, \mathrm{h}, \mathrm{in}}\right)=\dot{C}_{\mathrm{a}, \mathrm{h}}\left(T_{\mathrm{a}, \mathrm{h}, \text { out }}-T_{\mathrm{a}, \mathrm{h}, \text { in }}\right)
\end{gathered}
$$

The net cooling capacity is equal to the cooling capacity generated by the AMR minus the power consumption of the cold heat exchanger fan. Thus:

$$
\dot{Q}_{\mathrm{c}, \mathrm{net}}=\dot{Q}_{\mathrm{c}}-\dot{W}_{\mathrm{fan}, \mathrm{c}}
$$

where $\dot{W}_{\text {fan,c }}$ is obtained via the heat exchanger air-side hydraulic model presented below. Furthermore, the thermal load through the walls of the wine cooler cabinet is modelled using an equation similar to Eq. (4). The relation between the heat load and the net cooling capacity dictates the dynamics of the temperature inside the refrigerated space.

In the heat exchanger thermal hydraulic model, the air-side pressure drop is computed using the following expression, neglecting the entrance pressure loss and the exit pressure rise (Shah \& Sekulić 2003):

$$
\Delta P=\frac{G^{2}}{2 \rho_{\text {in }}}\left[2\left(\frac{\rho_{\text {in }}}{\rho_{\text {out }}}-1\right)+f \frac{A_{\text {ext }}}{A_{\min }} \frac{\rho_{\text {in }}}{\rho_{\text {avg }}}\right]
$$

where $A_{\text {ext }}$ is the air-side heat transfer area and $A_{\min }$ is the minimum air-side free-flow area (Shah \& Sekulic 2003). The Fanning friction factor, $f$, was calculated using the correlation of Wang et al. (2000) for herringbone wavy fin-tube heat exchangers. A similar procedure was adopted to calculate the pumping power associated with the in-tube liquid flow. In this case, relationships due to Churchill (1977) and Petukhov (1970) were used for laminar and turbulent flows, respectively. Additional localized pressure loss terms are used to compute the pressure drop in the return bends.

The heat exchanger effectiveness is computed using the ESDU (Engineering Sciences Data Unit) correlations for cross flow heat exchangers with either one tube row (Wang \& Chi 2000):

$$
\varepsilon=\frac{1}{C^{*}}\left[1-e^{-C^{*}\left(1-e^{-N T U}\right)}\right]
$$

or two tube rows:

$$
\varepsilon=\frac{1}{C^{*}}\left[1-e^{-2 K C^{*}}\left(1+C^{*} K^{2}\right)\right]
$$


where

$$
K=1-e^{\frac{-\mathrm{NTU}}{2}}
$$

The number of transfer units and the thermal capacity ratio are defined as:

$$
\begin{gathered}
N T U=\frac{U A_{\text {HEx }}}{\dot{C}_{\text {min }}} \\
C^{*}=\frac{\dot{C}_{\text {min }}}{\dot{C}_{\text {max }}}
\end{gathered}
$$

For a tube-fin heat exchanger, the overall thermal conductance is given by (Kakaç \& Liu 2002):

$$
U A_{\mathrm{HEx}}=\left[\left(\frac{1}{\eta_{\mathrm{fin}} h A}\right)_{\mathrm{ext}}+\frac{1}{2 \pi L N_{\mathrm{t}} k_{\mathrm{t}}} \ln \left(\frac{D_{\mathrm{o}}}{D_{\mathrm{i}}}\right)+\left(\frac{1}{h A}\right)_{\mathrm{int}}\right]^{-1}
$$

where the air-side heat transfer coefficient is defined in terms of the Colburn $j$-factor as follows,

$$
h_{\text {ext }}=j G_{\max } C_{\mathrm{p}, \mathrm{a}} \operatorname{Pr}_{\mathrm{a}}^{-2 / 3}
$$

where $j$ was computed using the correlation due to Wang et al. (2000). The internal convective heat transfer coefficient was computed via the Gnielinski correlation (Incropera \& DeWitt 2006). The finned surface efficiency was calculated using the Schmidt approximation (Perrotin \& Clodic 2003).

In Eq. (16), the geometric characteristics of the heat exchangers needed to evaluate the internal and external heat transfer areas (see Fig. 3) are calculated according to the relations given by Shah \& Sekulić (2003).

The validity of the methods and correlations used to compute the air-side heat transfer and pressure drop of herringbone wave-type tube-fin heat exchangers was verified against experimental data obtained in a wind tunnel calorimeter (Boeng et al. 2020) for heat exchanger Samples 2 and 5 , over a range of conditions similar to the present in situ experiments. Average errors of the order of $10 \%$ have been observed.

In the present model, to be consistent with the characteristics of the heat exchanger samples evaluated experimentally, the air-side frontal (face) area, tube size and tube pitch (transversal and longitudinal), and the inner and outer tube diameters were kept fixed, as summarized in Table I. Besides, the number of rows and fin density are identical to those evaluated experimentally and given by Table II. For simplicity, the cold and hot heat exchangers were assumed identical.

The head curves for the fan used in the experiments were utilized to define the operating points of the heat exchanger/fan assembly. Hence, the coupling of each heat exchanger in Table II with the fan results in three operating points, defined by the three rotation speeds.

\section{AMR model}

As mentioned in the previous section, the performance of the cabinet and heat exchanger model can be evaluated using input data from the AMR emulator or from the AMR model. In the latter case, the AMR was simulated using a modelling framework which has been extensively validated against experimental data. The model solves one-dimensional forms of the energy equations for the solid and fluid phases and the fluid momentum equation to describe the reciprocating flow in the regenerator 
beds. The reader is referred to Trevizoli et al. (2016b) for a full description of the model, boundary conditions and mathematical implementation.

In the present paper, we employ the above mentioned model to simulate the operating conditions of a wine cooler AMR system that is currently being commissioned at Universidade Federal de Santa Catarina (Lozano et al. 2018). The basic AMR design parameters are summarized in Table V. For simplicity, the dead volumes between the beds and the heat exchangers were neglected and each regenerator bed was assumed to be perfectly insulated.

Table V. AMR parameters used in the numerical simulation.

\begin{tabular}{|l|c|}
\hline Parameter & Value \\
\hline Number of regenerator beds & 8 \\
Regenerator bed length & $70 \mathrm{~mm}$ \\
Regenerator bed height & $19 \mathrm{~mm}$ \\
Regenerator bed width & $30 \mathrm{~mm}$ \\
Particle diameter & $0.435 \mathrm{~mm}$ \\
Mass flow rate per regenerator (Min/Max) & $\mathrm{okg} \mathrm{h}-1 / 75 \mathrm{~kg} \mathrm{~h}$ \\
Operating frequency & $1 \mathrm{~Hz}$ \\
Hot reservoir temperature & $298.15 \mathrm{~K}\left(25^{\circ} \mathrm{C}\right)$ \\
Cold reservoir temperature & $278.15 \mathrm{~K}\left(5^{\circ} \mathrm{C}\right)$ \\
Magnetic field (Min/Max) & $0 \mathrm{~T} / 1.15 \mathrm{~T}$ \\
Gd Curie Temperature & $290 \mathrm{~K}\left(17^{\circ} \mathrm{C}\right)$ \\
Magnetic field fraction & $35 \%$ \\
Fluid flow fraction & $25 \%$ \\
\hline
\end{tabular}

Moreover, in order to evaluate the influence of the heat exchangers on the overall wine cooler performance, the AMR parameters shown in Table $V$ are kept fixed, while only the geometric characteristics of the heat exchangers are systematically varied. The AMR system is composed of eight regenerator beds, which are modeled as rectangular cross-section homogeneous packed beds of monodisperse Gd spheres, as shown in Table V. The coupling between the magnetic and hydraulic profiles is presented in Fig. 5, where the minimum and maximum magnetic fields and mass flow rates are also presented in Table $V$. The magnetic field fraction, $F_{B}$, and the fluid flow fraction, $F_{F}$, are defined based on the total cycle period as follows (see Fig. 5):

$$
F_{B}=\frac{\tau_{B}}{\tau} ; F_{F}=\frac{\tau_{F}}{\tau}
$$

Since the maximum mass flow rate in each regenerator bed is constant and there is no overlapping of the fluid flow through neighboring regenerators, the mass flow rate through the hot and cold heat exchangers, which is equal to the mass flow rate through the pump, is related to the mass flow rate through a single regenerator by the following equation:

$$
\dot{m}_{\text {pump }}=\dot{m}_{1, \mathrm{HEx}}=\dot{m}_{\mathrm{l}, \mathrm{max}} N_{\text {reg }} F_{\mathrm{F}}
$$




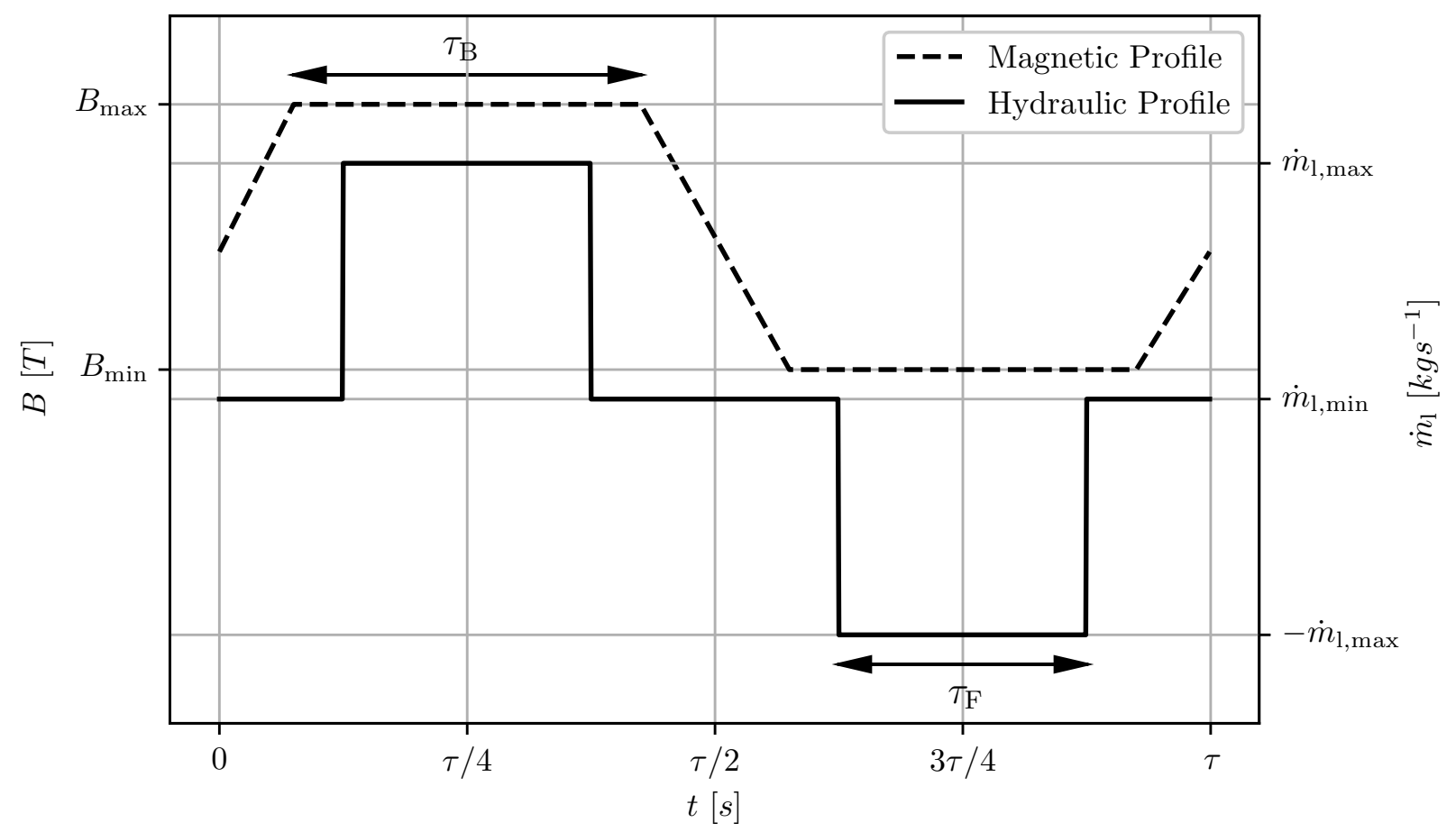

Figure 5. Comparison between the magnetic and hydraulic profiles.

The total input power can be broken down into four components, namely the magnetization of the solid refrigerant, liquid and air pumping, and hydraulic system (i.e., valves):

$$
\dot{W}=\dot{W}_{\text {mag }}+\dot{W}_{\text {pump }}+\dot{W}_{\text {fan }}+\dot{W}_{\text {valv }}
$$

The solid magnetization power is due to the magnetocaloric effect and can be calculated by (Kitanovski et al. 2015):

$$
\dot{W}_{\text {mag }}=m_{s} f_{\mathrm{r}} \oint T d s
$$

There are several methods to perform the hydraulic management of magnetocaloric refrigerators. In this analysis, electrovalves were chosen for their flexibility and reduced power consumption. The design is such that each pair of electrovalves controls two regenerators. Since the selected valves consume power only while they are open (Nakashima et al. 2018), the associated power consumption is given by:

$$
\dot{W}_{\text {valv }}=2 N_{\text {reg }} \dot{W}_{\text {nom }} F_{\mathrm{F}}
$$

where $\dot{W}_{\text {nom }}$ is the nominal power consumption of each electrovalve, estimated from actual data at 1.5 W (Nakashima et al. 2018).

The liquid pumping power is given by:

$$
\begin{aligned}
\dot{W}_{\text {pump }} & =\frac{N_{\text {reg }} \dot{m}_{\text {l,max }} F_{\mathrm{F}}}{\eta_{\text {pump }}} \times \\
& {\left[2\left(\frac{\Delta P}{\rho}\right)_{\text {AMR }}+\left(\frac{\Delta P}{\rho}\right)_{\text {CHEx }, \text { int }}+\left(\frac{\Delta P}{\rho}\right)_{\text {HHEx,int }}\right] }
\end{aligned}
$$


where the first term corresponds to the regenerator beds (hot and cold blows) and the second and third terms are due to the hot and cold heat exchangers.

The AMR bed pressure drop was computed using the correlation proposed by Ergun (1952), while the heat exchanger liquid-side pressure drop was computed via Eq. (10). The overall pump efficiency was estimated at $70 \%$.

The fan power consumption of both hot and cold heat exchangers is calculated similarly to the pumping power and is given by:

$$
\dot{W}_{\mathrm{fan}}=\dot{W}_{\mathrm{fan}, \mathrm{c}}+\dot{W}_{\mathrm{fan}, \mathrm{h}}=\left(\frac{\Delta P \dot{m}_{\mathrm{a}, \mathrm{fan}}}{\eta_{\mathrm{fan} \rho_{\mathrm{a}}}}\right)_{\mathrm{CHEx,ext}}+\left(\frac{\Delta P \dot{m}_{\mathrm{a}, \mathrm{fan}}}{\eta_{\mathrm{fan} \rho_{\mathrm{a}}}}\right)_{\text {HHEx,ext }}
$$

where the fan overall efficiency was estimated at 10\% and the air-side pressure drop was calculated using Eq. (10).

Analogously to the conventional wine cooler refrigeration system, a cooling capacity control strategy was implemented assuming on-off behavior, with the duty cycle (i.e., the fraction of the time when the system is on) being computed as the ratio of the heat load (Eq. 4) to the net cooling power (Eq. 9). Through an energy balance in the cabinet over the period of one on-off cycle, the duty cycle can be calculated as:

$$
D C\left(\dot{Q}_{\mathrm{c}}-\dot{W}_{\mathrm{fan}, \mathrm{c}}\right)=(U A)_{\mathrm{cab}}\left(\bar{T}_{\mathrm{amb}}-\bar{T}_{\mathrm{cab}}\right)
$$

Therefore, the mean power consumption is given by the product of the total input power, Eq. (20), and the duty cycle as follows:

$$
\overline{\mathrm{W}}=\dot{W}\left[\frac{(U A)_{\mathrm{cab}}\left(\bar{T}_{\mathrm{amb}}-\bar{T}_{\mathrm{cab}}\right)}{\dot{Q}_{\mathrm{c}}-\dot{W}_{\mathrm{fan}, \mathrm{c}}}\right]
$$

The coefficient of performance and the second-law efficiency are defined as:

$$
\begin{gathered}
\mathrm{COP}=\frac{\dot{Q}_{\mathrm{c}}}{\dot{W}} \\
\eta_{2 \mathrm{nd}}=\operatorname{COP}\left(\frac{\bar{T}_{\mathrm{amb}}-\bar{T}_{\mathrm{cab}}}{\bar{T}_{\mathrm{cab}}}\right)
\end{gathered}
$$

\section{Solution procedure}

There are two different approaches to couple the AMR and heat exchanger models described previously. In the first, the thermal reservoir temperatures are used as boundary conditions. In the second, the boundary conditions are the inlet AMR temperatures.

The first approach is suggested for problems involving sizing of thermal systems, heat exchangers and regenerator design, when the reservoir temperatures are fixed, such as the analysis developed in this work. When using the thermal reservoir temperatures as boundary conditions, numerical iteration is necessary to converge the fluid temperatures and determine the cooling capacity (and the heat rejection rate) from both the AMR and cold (and hot) heat exchanger models. However, because of the iterative process, this method can be more computationally expensive. For instance, the input temperatures to the AMR model, namely the temperatures at the cold end during the cold blow, $T_{1, c, o u t}$, and at the hot end during the hot blow, $T_{1, h \text {,out }}$, are the output temperatures of the heat exchanger 
model. Conversely, the outlet temperatures at the hot end during the cold blow, $T_{l, h, i n}$, and at the cold end during the hot blow, $T_{1, \mathrm{c}, \mathrm{in}}$, are inputs to the heat exchanger model (see Section Cabinet and heat exchanger model) and outputs of the AMR model. Hence, numerical convergence of temperatures guarantee that the cooling capacity and heat rejection rate are calculated in both the AMR and heat exchanger models.

\section{RESULTS}

\section{Cabinet and heat exchanger model performance}

Prior to assessing the influence of the cabinet and heat exchangers on the performance of the AMR model, one needs to quantify the accuracy of the cabinet thermal model with respect to the experimental data for the cabinet/AMR emulator assembly. Fig. 6 compares the experimental data and modelling results for the average cabinet air temperature and for the temperature difference between the cabinet air and the ambient air, i.e. the temperature span. A good agreement has been found for both variables as a function of the cold heat exchanger liquid inlet temperature, $T_{1, \mathrm{c}, \text { in }}$ (the independent variable).

In general, the largest deviations between model and data were observed for the heat exchanger samples with one tube row (Samples 1, 2 and 3). The temperature stratification inside the cabinet (i.e., the difference between temperatures measured by three thermocouples, see Fig. 3) was between $0.3^{\circ} \mathrm{C}$ and $0.6^{\circ} \mathrm{C}$.

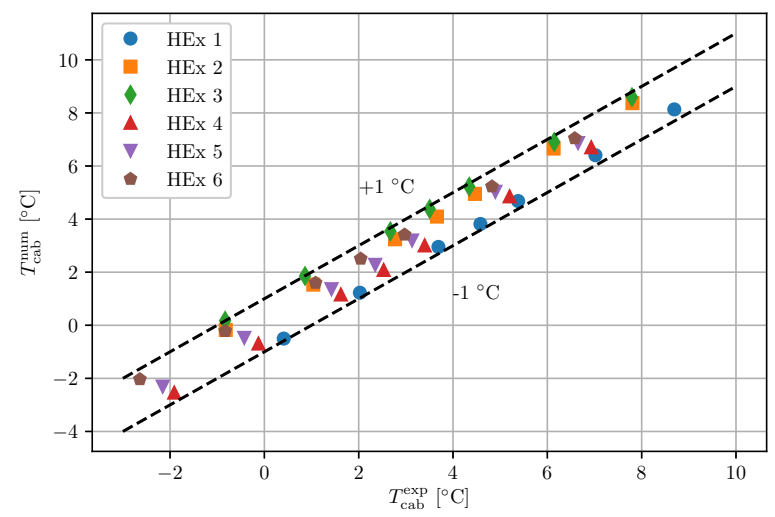

(a)

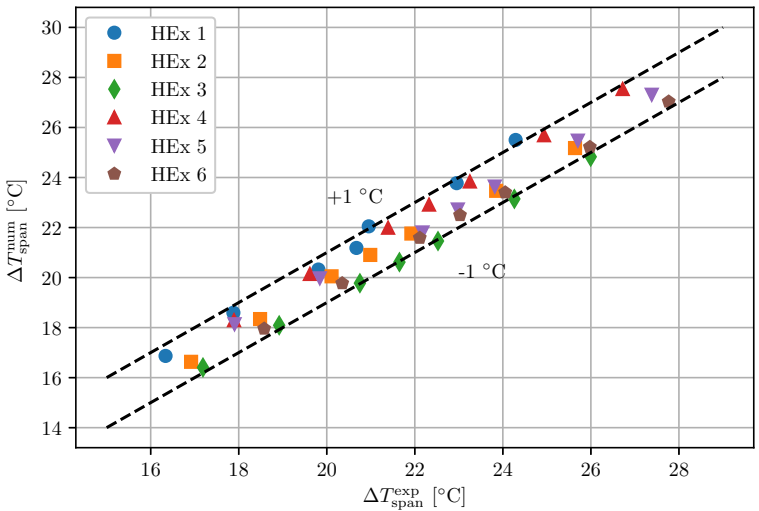

(b)

Figure 6. Comparison between the steady-state experiments performed for the six heat exchanger-fan combinations. (a) Average cabinet temperature; (b) Temperature difference between sources (temperature span). Note that the error bars associated with the temperature measurements are smaller than the markers and are, therefore, not visible.

The capability of the cabinet and heat exchanger model to predict the system cooling capacity (cabinet thermal load) to within a $5 \%$ error margin is shown in Fig. 7. As expected, for a fixed value of $T_{1, c, \text { in }}$, the general trend is that the heat transfer rate increases with the air-side surface area (which appears to be more important than the air flow rate, for the range of parameters evaluated). Thus, Sample 6 presents the largest cooling capacity and Sample 1 the lowest. 


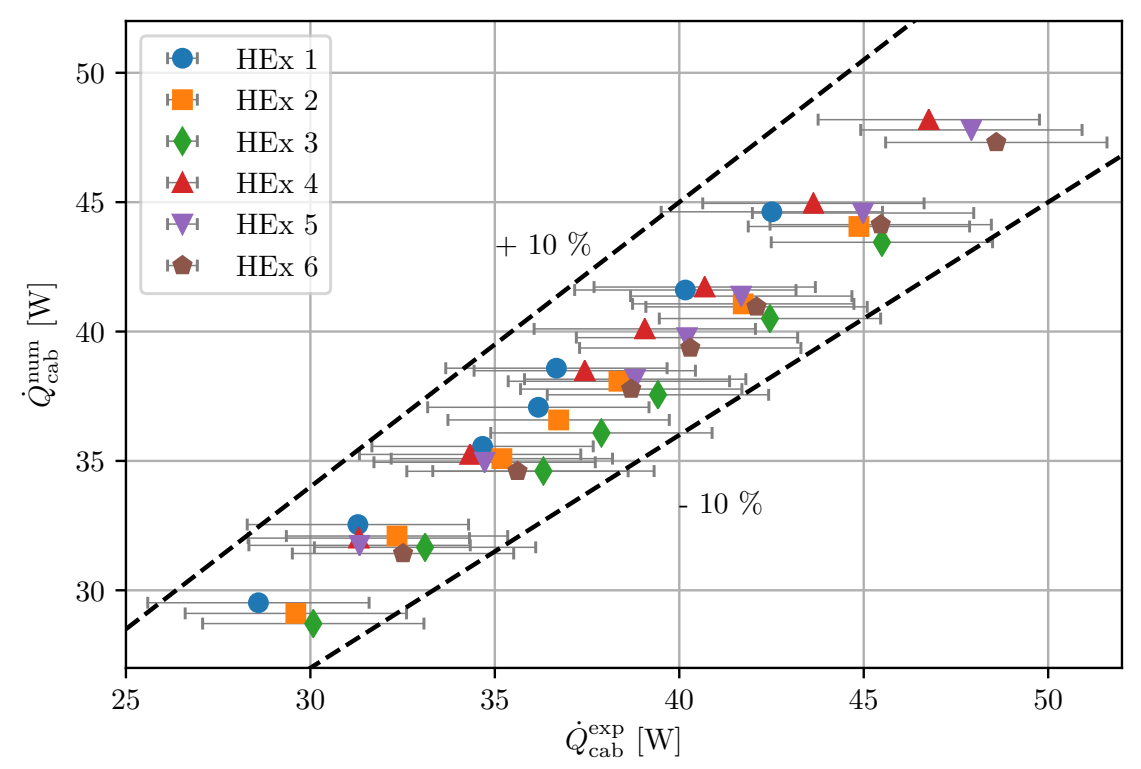

Figure 7. Steady-state cooling capacity (cabinet thermal load) predictions for the six heat exchanger-fan combinations. Note that the error bars represent an uncertainty of $3 \mathrm{~W}$.

\section{AMR modeling results}

\section{Heat exchanger performance}

The temperature variation experienced by the liquid stream in both heat exchangers and its impact on the AMR cooling capacity and thermodynamic efficiency is evaluated in terms of the liquid-side effectiveness, $\varepsilon C^{*}$, which is defined - using Eqs. (5) and (6) - as the dimensionless liquid-side temperature change (Shah \& Sekulić 2003):

$$
\left(\varepsilon C^{*}\right)_{\mathrm{c}}=\left(\varepsilon C^{*}\right)_{\mathrm{h}}=\left(\varepsilon C^{*}\right)=\left(\frac{\dot{C}_{\mathrm{a}}}{\dot{\bar{C}}_{\mathrm{l}}} \varepsilon\right)=\left(\frac{\Delta T_{\mathrm{l}}}{\Delta T_{\max }}\right)
$$

since the temperature changes in the current system do not result in substantial properties variation in the liquid and air, an initial assumption is to consider the values of the liquid side effectiveness, for both the hot and cold samples, to be the same.

The influence of the heat exchanger independent variables (number of tube rows, fin density, and volumetric air flow rate) on the liquid stream effectiveness is shown in Fig. 8. The three markers along each curve correspond to the operating points of the heat exchanger/fan assembly at the low, medium and high fan speeds. As can be seen, samples with two tube rows are capable of achieving higher values of $\varepsilon C^{*}$ than the ones with a single row. Although the single row units operate at higher air flow rates, the heat exchangers with two rows have a much larger surface area, which has a much more significant impact on the liquid-side effectiveness.

The behavior of the air-side pumping power is illustrated in Fig. 9. It is clear that increasing the number of rows or the fin density increases the fan pumping power due to the larger frictional pressure drop associated with the larger surface area. Although high flow rates are desirable from a heat transfer standpoint, they are related to an increase in fan power which, as will be demonstrated, not only deteriorates the performance of the system by increasing the overall energy consumption, but also generates an extra heat load in the cold environment. Again, the three markers on each curve 

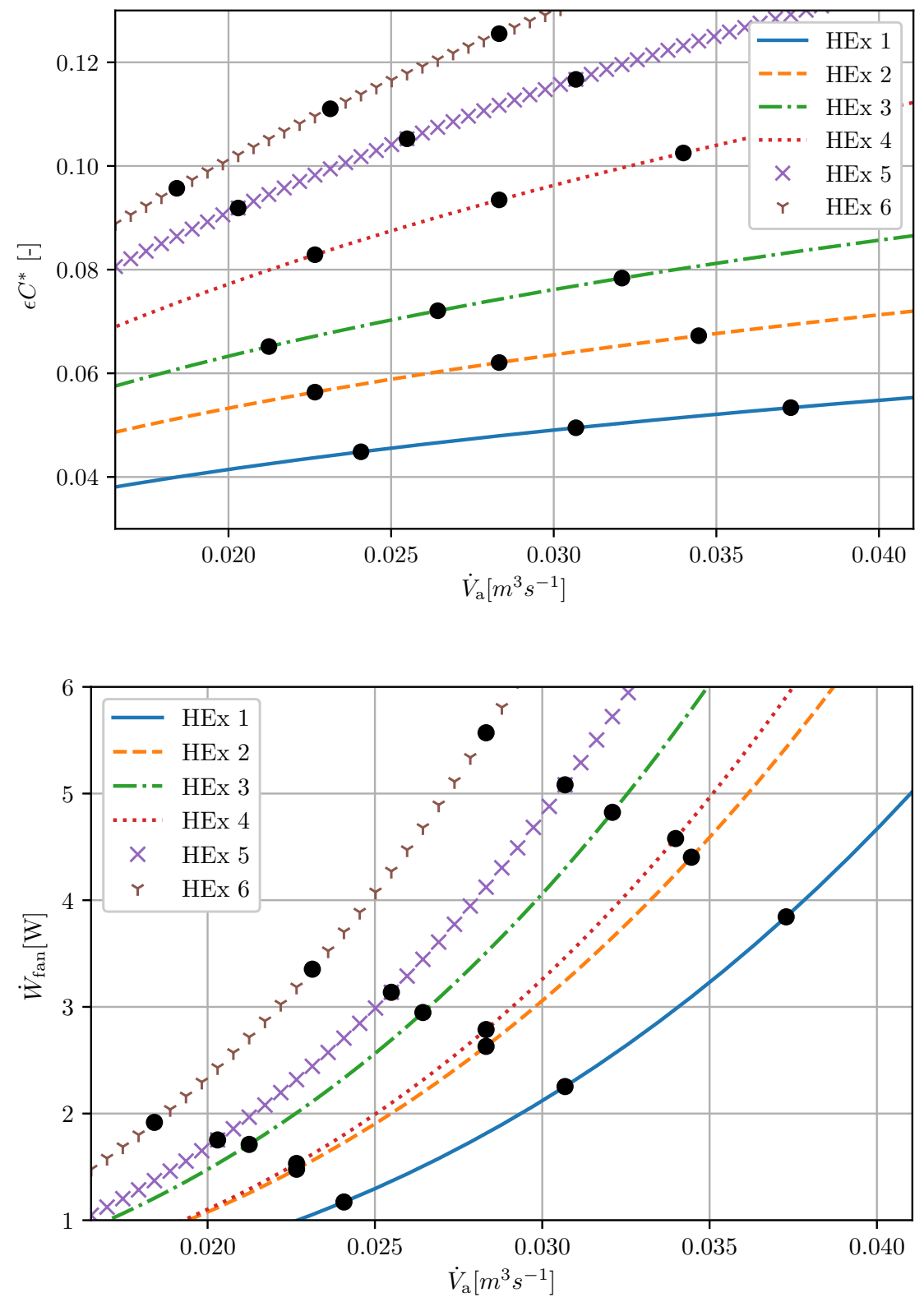

Figure 8. Effect of the heat exchanger geometry and operating conditions on the liquid stream effectiveness. The three markers along each curve correspond to the operating points of the heat exchanger/fan assembly.

Figure 9. Effect of the heat exchanger geometry and operating conditions on the fan power consumption. The three markers along each curve correspond to the operating points of the heat exchanger/fan assembly.

correspond to the three operating points of the heat exchanger/fan assembly. The liquid-side pumping power was approximately $0.27 \mathrm{~W}$ and $0.55 \mathrm{~W}$ for the heat exchanger of 1 and 2 rows, respectively.

\section{Influence of the heat exchangers on the system performance}

Having determined the ranges of liquid-side effectiveness and pumping power obtained with the heat exchanger/fan assemblies, Fig. 10 shows how $\varepsilon C^{*}$ (assumed, for simplicity, equal for both heat exchangers) affects the calculated cooling capacity and the regenerator temperature span for the present AMR system at a system temperature span of $20^{\circ} \mathrm{C}$. The green band between approximately 0.042 and 0.124 corresponds to the range of $\varepsilon C^{*}$ resulting from the operating points of the heat 
exchangers/fan assemblies tested in this work and shown on the curves of Fig. 8. It becomes clear that the system performance is strongly affected by $\varepsilon C^{*}$, particularly for values below 0.4 , i.e., a substantial increase of the AMR temperature span is required to compensate the reduction of the heat exchanger overall thermal conductance and maintain the system temperature span at $20^{\circ} \mathrm{C}$. This obviously contributes to increasing the external losses of the magnetic cooling system, which reduces the overall system efficiency. However, as will be seen below, increasing the heat exchanger size or the fan power to obtain higher values of NTU and liquid-side effectiveness will affect the overall power consumption in other ways so that an optimum $\varepsilon C^{*}$ will be found by using a specific heat exchanger at a specific operating point.

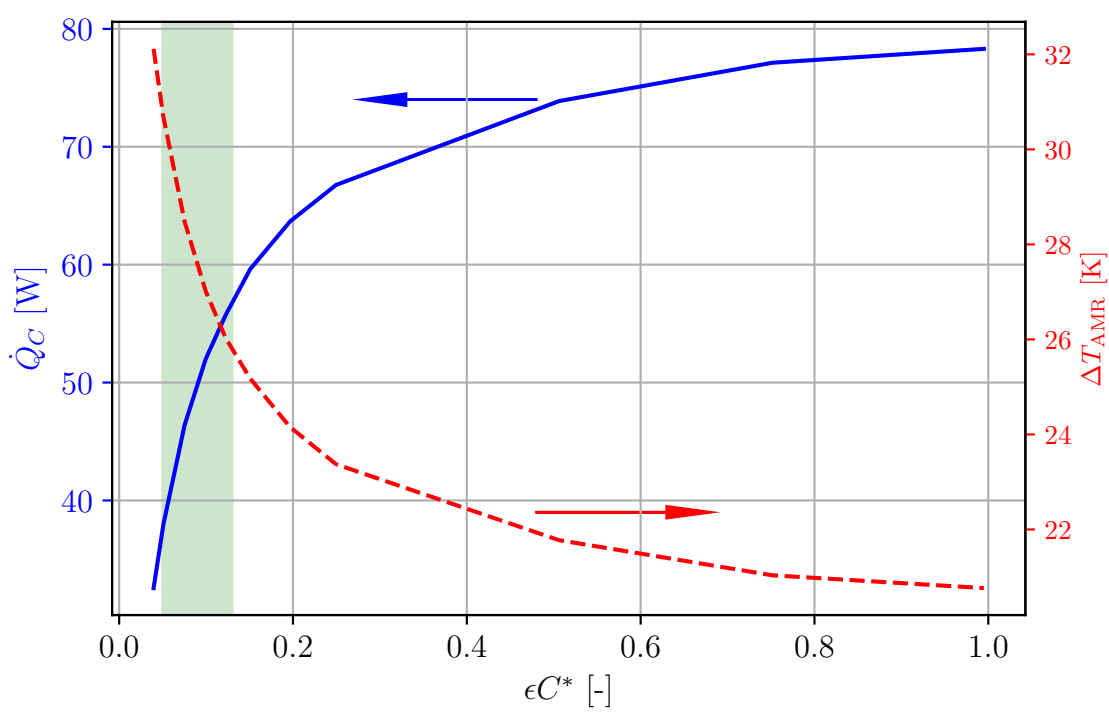

Figure 10. Influence of the heat exchanger effectiveness on the AMR cooling capacity and temperature span for a system temperature span of $20^{\circ} \mathrm{C}$. The green band corresponds to the range of $\varepsilon C^{*}$ resulting from the operating points of the heat exchangers/fan assemblies tested in this work.

Fig. 11 shows the behavior of the net cooling capacity, $\dot{Q}_{\mathrm{C}, \text { net }}$, as a function of the total fan power for both heat exchangers. It is clear that increasing the air flow rate of the heat exchanger will not necessarily increase $\dot{Q}_{\mathrm{C} \text {,net }}$ as a result of the parasitic thermal load imposed by the cold side fan.

Fig. 11 also illustrates some important aspects of the interaction between the AMR and the heat exchangers in the magnetic refrigeration system. Firstly, at low pumping powers, a small increase in the fan pumping power can lead to significant returns in terms of cooling capacity due to the steep inclination of the cooling capacity with respect to $\varepsilon C^{*}$, as shown in Fig. 10. As the pumping power increases, the slope of the net cooling capacity curve decreases due to the decreasing slope of the cooling capacity curve in Fig. 10. Thus, the curve reaches a peak as a result of the trade-off between the increase in cooling capacity and power dissipation of the fan. As far as the heat exchanger geometry is concerned, a higher number of tube rows can generate higher net cooling capacities with the same pumping power, representing better design options. Even though there is some overlapping in the low pumping power regions, higher values of fin density usually resulted in higher net cooling capacities. Considering only the heat exchanger/fan assembly and its three operating points, the highest fan speed gives operating points close to the peak, where the influence of the fan speed on the net cooling capacity is small. 


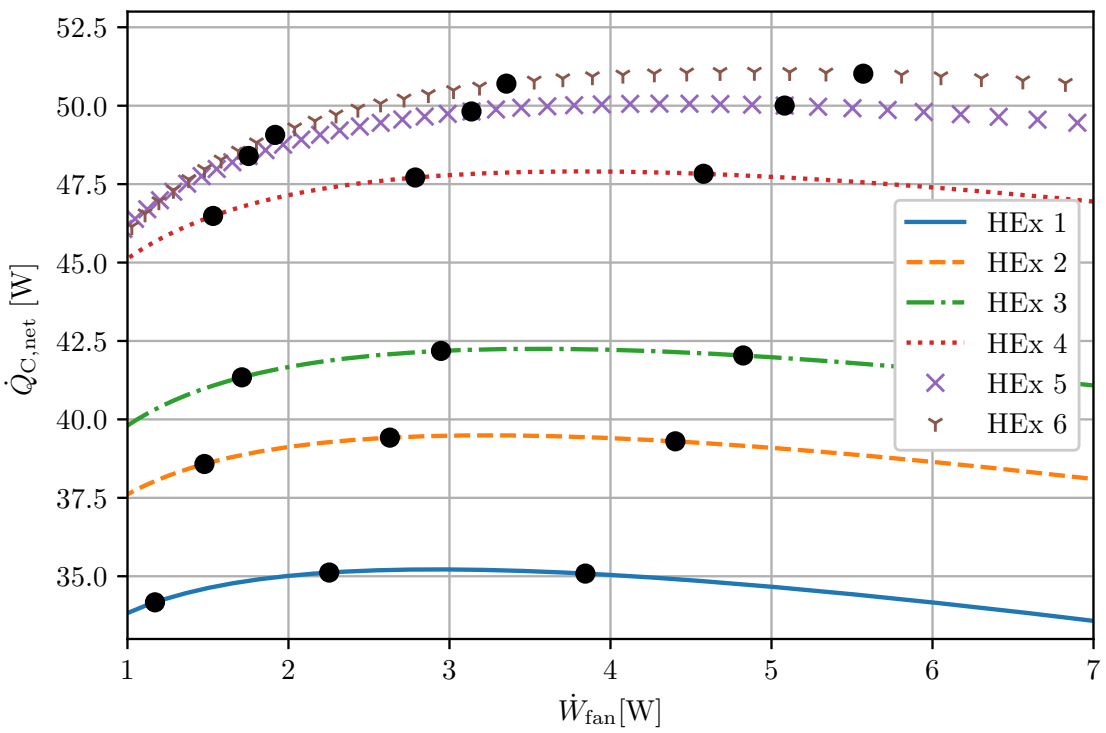

Figure 11. Net cooling capacity as a function of the total fan pumping power. The three markers along each curve correspond to the operating points of the heat exchanger/fan assembly.

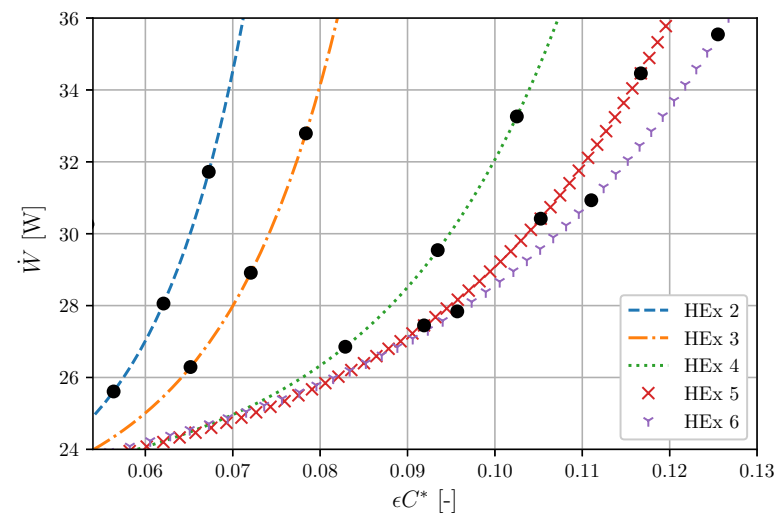

(a)

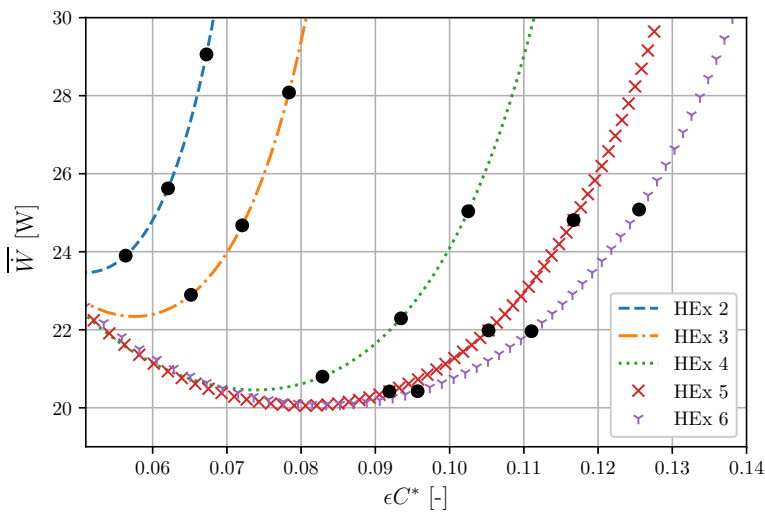

(b)

Figure 12. Power consumption of the system. (a) Instantaneous; (b) Average. The three markers along each curve correspond to the operating points of the heat exchanger/fan assembly.

Fig. 12 shows the behavior of the instantaneous and average power consumption, given, respectively, by Eqs. (20) and (26), as a function of the liquid stream effectiveness. Since, according to Fig. 11, heat exchanger Sample 1 was not able to achieve a net cooling capacity equal to the design thermal load of $35.6 \mathrm{~W}$, it would not be able to supply the system with the desired conditions, so it is not presented in this figure.

Given that the regenerator geometry, thermal fluid mass flow rate and frequency were kept fixed in this analysis, the power consumption associated with liquid pumping and valve operation remain almost unchanged for each heat exchangers evaluated. On the other hand, the fan and magnetic power consumption contributions exhibit significant changes as a result of the variations in heat exchanger geometry and air flow rate, which have a direct impact on the regenerator temperature span and cooling capacity. Besides that, it should be mentioned that the system duty cycle also 
changes (between $70 \%$ and 95\%, approximately) in response to the variation in the net cooling capacity presented in Fig. 11.

As can be seen in Fig. 12 (a), the instantaneous power consumption of the system increases monotonically with the air flow rate, number of tube rows and fin density. However, the trend is somewhat different for the average power consumption, as seen in Fig. 12 (b), which shows a clear trade-off caused by the increase in power consumption and a reduction of the duty cycle provoked by the rise in the net cooling capacity.

The lowest average power consumption was achieved with the heat exchanger Sample 6 operating at the lowest fan speed. For this reason, a detailed performance breakdown will be presented for the system operating with this heat exchanger. Firstly, by comparing the performance of a system equipped with ideal heat exchangers (for which $\varepsilon C^{*}=1$ ) with the actual system (i.e., with Sample 6), one observes a decrease in cooling capacity from 78.3 to $49.2 \mathrm{~W}$ (37\%) and an increase in the regenerator temperature span from 20.7 to $27.3^{\circ} \mathrm{C}$ (see Fig. 10).

Fig. 13 presents the power breakdown of a wine cooler driven by a magnetic refrigeration system operating with the heat exchanger/fan assembly Sample 6 and the AMR described in detail in Table $\mathrm{V}$. Since the average power consumption of the system is $20.5 \mathrm{~W}$ and cooling capacity is $37 \mathrm{~W}$, this leads to a coefficient of performance (COP) of 1.8 and a second-law efficiency, $\eta_{2 n d}$, of $13 \%$. The solid magnetization has the highest individual contribution to the total power consumption (36.1\%), part of which is converted to cooling capacity on the cold side. Fluid friction, on the other hand, takes up more than $42 \%(8.61 \mathrm{~W})$ of the total average power when the liquid and air sides are combined. The hydraulic management system also contributes with a significant share of the total power, indicating that there is room for improvement in this area with the use of low-power valve systems.

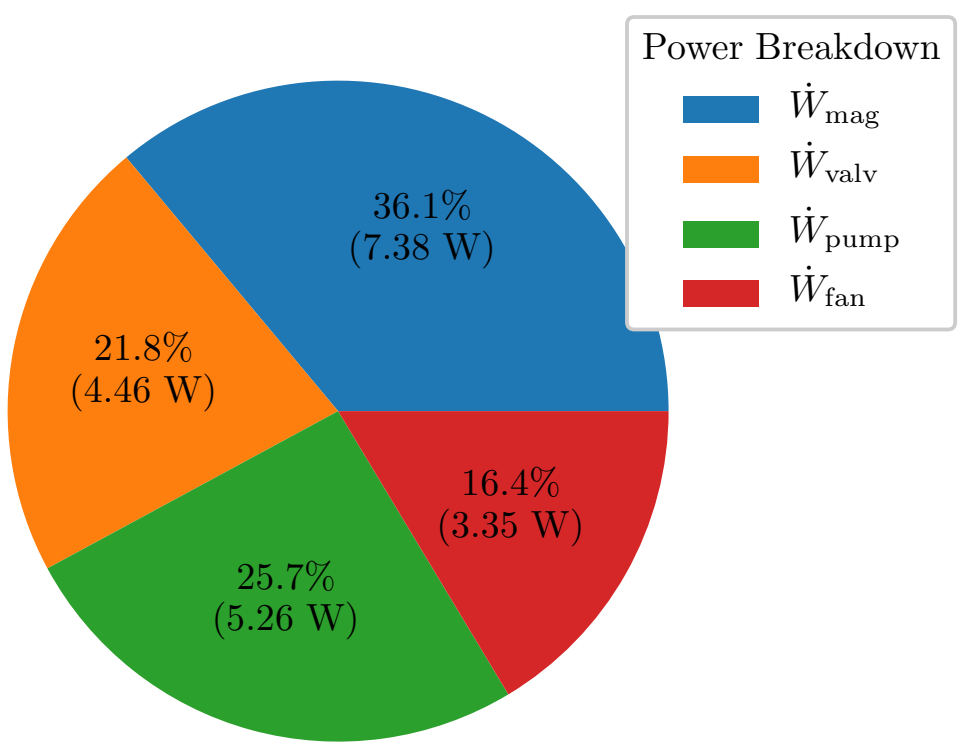

Figure 13. Average power breakdown for a wine cooler driven by a magnetic refrigeration system coupled with the heat exchanger/fan assembly Sample 6. 


\section{CONCLUSIONS}

This paper evaluated experimentally and theoretically the influence of the heat exchangers on the thermal performance of a compact wine cooler driven by a magnetic refrigeration system.

Firstly, an experimental apparatus was developed to emulate the operating conditions (temperature and flow rate) of the heat transfer fluid delivered to the hot and cold heat exchangers by the AMR. The apparatus was coupled to a retrofitted wine storage cabinet equipped with different fan-supplied tube-fin heat exchangers to evaluate the impact of their geometry and operating parameters on the cooling capacity and average cabinet air temperature. A mathematical model was developed to describe the steady-state heat transfer in the cabinet using the $\varepsilon$-NTU method to calculate the thermal-hydraulic behavior of the tube-fin heat exchangers. The model was validated against experimental data and deviations of the order of $1^{\circ} \mathrm{C}$ were obtained for the average cabinet air temperature and system temperature span. Deviations for the model cooling capacity were inferior to $5 \%$.

The cabinet and heat exchanger model was integrated with an existing AMR numerical model and numerical simulations were carried out to predict the thermal performance of a magnetic refrigerator in response to the different characteristics of the six tube-fin heat exchanger samples. The analysis was centered on the so-called liquid stream effectiveness, $\varepsilon C^{*}$, and the behavior of the net cooling capacity and fan power consumption as a function of $\varepsilon C^{*}$ demonstrated that a heat exchanger with multiple tube rows and a large fin density would result in better system performances. When compared to the performance of a magnetic refrigerator equipped with ideal heat exchangers, a $37 \%$ reduction on the cooling capacity followed by a $32 \%$ increase of the system temperature span was obtained.

\section{List of symbols}

Roman
$A$
$B$
$\dot{C}$
$C^{*}$
$C_{\mathrm{p}}$
$D$
$D C$
$F$
$f$
$f_{\mathrm{r}}$
$G$
$H$
$h$
$j$
$k$
$L$
$m_{\mathrm{s}}$
$\dot{m}$
$N$
$N T U$
$P r$
$P$
$\dot{Q}_{\mathrm{C}}$

area, $\mathrm{m}^{2}$

magnetic Field, $\mathrm{T}$

thermal capacity rate, $\mathrm{W} \mathrm{K}^{-1}$

thermal capacity rate ratio

isobaric specific heat capacity, J $\mathrm{kg}^{-1} \mathrm{~K}^{-1}$

diameter, $m$

duty cycle

fraction

friction factor

frequency, $\mathrm{s}^{-1}$

mass flux, $\mathrm{kg} \mathrm{m}^{-2} \mathrm{~s}^{-1}$

height, $m$

convective heat transfer coefficient, $\mathrm{W} \mathrm{m}^{-2} \mathrm{~K}^{-1}$

colburn factor

thermal conductivity, $\mathrm{W} \mathrm{m}^{-1} \mathrm{~K}^{-1}$

length, m

solid mass, kg

mass flow rate, $\mathrm{kg} \mathrm{s}^{-1}$

number

number of transfer units

Prandtl number

pressure, $\mathrm{Pa}$

cooling capacity, w

$\begin{array}{ll}\dot{Q}_{\text {cab }} & \text { heat loss through the cabinet wall, W } \\ \dot{Q}_{\mathrm{h}} & \text { heat rejection rate, } \mathrm{W} \\ \mathrm{S} & \text { specific entropy, } \mathrm{kg}^{-1} \mathrm{~K}^{-1} \\ T & \text { temperature, } \mathrm{K},{ }^{\circ} \mathrm{C} \\ \cup A & \text { overall thermal conductance, } \mathrm{W} \mathrm{K} \mathrm{K}^{-1} \\ \dot{V} & \text { volumetric flow rate, } \mathrm{m}^{3} \mathrm{~s}^{-1} \\ W & \text { width, } \mathrm{m} \\ \dot{W} & \text { power consumption, } \mathrm{W} \\ X_{\mathrm{f}} & \text { fin pitch, } \mathrm{m} \\ X_{\mathrm{l}} & \text { longitudinal tube pitch, } \mathrm{m} \\ X_{\mathrm{t}} & \text { transversal tube pitch, } \mathrm{m} \\ \mathbf{G r e e k} & \\ \Delta & \\ \varepsilon & \text { variation } \\ \eta & \text { effectiveness } \\ \rho & \text { efficiency } \\ \varsigma & \text { density, } \mathrm{kg} \mathrm{m}^{-3} \\ \tau & \text { fin density, } \mathrm{m}^{-1} \\ & \text { period, } \mathrm{S}\end{array}$

\section{Subscripts}

a

amb ambient

avg average

bot bottom

B magnetic Field 


$\begin{array}{ll}\text { c } & \text { cold } \\ \text { cab } & \text { cabinet } \\ \text { CHEx } & \text { Cold heat exchanger } \\ \text { ext } & \text { external } \\ \text { fan } & \text { fan } \\ \text { fin } & \text { fin surface } \\ \text { F } & \text { fluid flow } \\ \text { h } & \text { hot } \\ \text { HHEx } & \text { hot heat exchanger } \\ \text { hyd } & \text { hydraulic } \\ \text { i } & \text { inner } \\ \text { in } & \text { inlet } \\ \text { int } & \text { internal } \\ \text { l } & \text { liquid } \\ \text { mag } & \text { magnetization } \\ \text { max } & \text { maximum } \\ \text { min } & \text { minimum } \\ \text { net } & \text { net } \\ \text { nom } & \text { nominal } \\ \text { o } & \text { outer } \\ \text { out } & \text { outlet } \\ \text { pump } & \text { pumping } \\ r & \text { row } \\ \text { reg } & \text { regenerator } \\ \text { span } & \text { system temperature span } \\ \text { t } & \text { tube } \\ \text { top } & \text { top } \\ \text { valv } & \text { valves } \\ & \\ & \end{array}$

\section{Superscripts}

$\begin{array}{ll}\text { exp } & \text { experimental } \\ \text { num } & \text { numerical } \\ \text { - } & \text { average }\end{array}$

\section{Abbreviations}

AMR active magnetic regenerator

HEX heat exchanger

MCE magnetocaloric effect

\section{Acknowledgments}

The primary sources of funding for this work were the CNPq (Conselho Nacional de Desenvolvimento Científico e Tecnológico, Grant no. 404023/2019-3), FAPESC (Fundação de Amparo à Pesquisa e Inovação do Estado de Santa Catarina, Grant no. 2019TRo846), CAPES (Coordenação de Aperfeiçoamento de Pessoal de Nivel Superior, Grant No. 88887.194773/2018-00), EMBRAPII (Empresa Brasileira de Pesquisa e Inovação Industrial) and Nidec Global Appliance Compressores e Soluções em Refrigeração Ltda. (formerly Embraco).

\section{REFERENCES}

ARORA A \& KAUSHIK S. 2008. Theoretical analysis of a vapour compression refrigeration system with $\mathrm{R}-502$, R-404A and R-507A. Int J Refrig 31: 998-1005.

BARCLAY JA \& STEYERT WA. 1982. Active Magnetic Regenerator. U.S. Patent 4332135A.

BJ $\varnothing$ RK R, BAHL C \& NIELSEN K. 2016. The lifetime cost of a magnetic refrigerator. Int J Refrig 63: 48-62.

BOENG J, MARCON A \& HERMES CJL. 2020. Air-side heat transfer and pressure drop characteristics of microchannel evaporators for household refrigerators. Int J Heat Mass Trans 147: 118913.

CALOMENO RS. 2018. Mathematical Modelling of the Cabinet and Heat Exchangers in a Domestic Wine Cooler Operated by a Magnetic Refrigerator. Master's thesis, Federal University of Santa Catarina, 166 p.

CALOMENO RS, LOZANO JA, TREVIZOLI PV \& BARBOSA JR JR. 2016. Influence of the heat exchangers thermal conductance on the thermodynamic performance of a magnetic refrigerator. In: Seventh IIF-IIR International Conference on Magnetic Refrigeration at Room Temperature.

CHAUDRON J-B, ELOUAD L, MULLER C, RISSER M \& VASILE C. 2014. Specific design of a heat exchanger for a functional magnetic refrigeration system. In: Proceedings in Sixth IIF-IIR International Conference on Magnetic Refrigeration, Victoria, BC.

CHURCHILL SW. 1977. Friction-factor equation spans all fluid-flow regimes. Chem Eng (New York) 84: 91-92.

ENGELBRECHT K. 2004. A numerical model of an active magnetic regenerator refrigeration system. Master's thesis, University of Wisconsin-Madison, $177 \mathrm{p}$.

ERGUN S. 1952. Fluid flow through packed column. Chem Eng Prog 48: 89-94.

GHOLAP A \& KHAN J. 2007. Design and multi-objective optimization of heat exchangers for refrigerators. Appl Energ 84: 1226-1239.

GONÇALVES JM, MELO C, HERMES CJL \& BARBOSA JR JR. 2011. Experimental mapping of the thermodynamic losses in vapor compression refrigeration systems. J Braz Soc Mech Sci Eng 33: 159-165.

GRECO A, APREA C, MAIORINO A \& MASSELLI C. 2019. A review of the state of the art of solid-state caloric cooling processes at room-temperature before 2019. Int I Refrig 106: 66-88. 
GSCHNEIDNER K \& PECHARSKY V. 2008. Thirty years of near room temperature magnetic cooling: Where we are today and future prospects. Int J Refrig 31: 945-961.

HERMES CJ, MELO C \& KNABBEN FT. 2013. Alternative test method to assess the energy performance of frost-free refrigerating appliances. Appl Therm Eng 50: 1029-1034.

HITTINGER M, CHAUDRON J-B, ELOUAD L, MULLER C, HAEGEL P \& VASILE C. 2016. Impact of the integration work on the performance measurements of the magnetocaloric cooling system and its target refrigerated cabinet. In: Seventh IIF-IIR International Conference on Magnetic Refrigeration at Room Temperature, THERMAG VII, Torino, Italy.

INCROPERA FP \& DEWITT DP. 2006. Fundamentals of Heat and Mass Transfer. J Wiley \& Sons, 6th ed, 997 p.

KAKAÇ S \& LIU H. 2002. Heat exchangers: Selection, Rating, and Thermal Design, 2nd ed, 520 p.

KAYS WM \& LONDON AL. 1984. Compact Heat Exchangers. McGraw-Hill, New York, USA, 335 p.

KITANOVSKI A, TUSEK J, TOMC U, PLAZNIK U, OBOLT M \& POREDOS A. 2015. Magnetocaloric Energy Conversion, From Theory to Applications. Springer, $477 \mathrm{p}$.

KLEIN SA \& REINDL DT. 1998. The relationship of optimum heat exchanger allocation and minimum entropy generation rate for refrigeration cycles. J Energ Resour-ASME 120: 172-178.

LOZANO JA ET AL. 2018. Polomag: Designing a magnetic wine cooler. In: Thermag VIII - International Conference on Caloric Cooling, p. 16-20, September, Darmstadt, Germany.

MELO C, DA SILVA LW \& PEREIRA RH. 2000. Experimental evaluation of the heat transfer through the walls of household refrigerators. In: Proc. International Refrigeration and Air Conditioning Conference at Purdue, number 1502.

MOROSUK T \& TSATSARONIS G. 2009. Advanced exergetic evaluation of refrigeration machines using different working fluids. Energy 34: 2248-2258.

NAKASHIMA AT, DUTRA S, HOFFMANN G, LOZANO JA \& BARBOSA JR JR. 2018. Performance Assessment of Solenoid Valves as Flow Distributors for an Active Magnetic Regenerator. In: Proceedings in Eighth IIR International Conference on Caloric Cooling, Thermag VIII, Darmstadt, Germany.

PERROTIN T \& CLODIC D. 2003. Fin efficiency calculation in enhanced fin-and-tube heat exchangers in dry conditions. In: Proceedings of the Twentieth International Congress of Refrigeration, Washington DC, paper ICROO26.

PETUKHOV B. 1970. Heat transfer and friction in turbulent pipe flow with variable physical properties. Adv Heat Trans 6: 503-564.

SHAH RK \& SEKULIĆ DP. 2003. Fundamentals of Heat Exchanger Design. J Wiley \& Sons, 976 p.

TREVIZOLI PV, CHRISTIAANSE TV, GOVINDAPPA P, NIKNIA I, TEYBER R, BARBOSA JR \& ROWE A. 2016a. Magnetic heat pumps: An overview of design principles and challenges. Sci Technol Built En 22: 507-519.

TREVIZOLI PV, NAKASHIMA AT \& BARBOSA JR JR. 2016b. Performance evaluation of an active magnetic regenerator for cooling applications - Part II: Mathematical modeling and thermal losses. Int J Refrig 72: 206-217.

WALTRICH PJ, BARBOSA JR JR \& HERMES CJL. 2011. COP-based optimization of accelerated flow evaporators for household refrigeration applications. Appl Therm Eng 31: 129-135.

WANG C-C \& CHI K-Y. 2000. Heat transfer and friction characteristics of plain fin-and-tube heat exchangers. Part I: New experimental data. Int J Heat Mass Trans 43: 2681-2691.

WANG C-C, CHI K-Y \& CHANG C-J. 2000. Heat transfer and friction characteristics of plain fin-and-tube heat exchangers. Part II: Correlation. Int J Heat Mass Trans 43: 2693-2700.

YU B, LIU M, EGOLF PW \& KITANOVSKI A. 2010. A review of magnetic refrigerator and heat pump prototypes built before the year 2010. Int J Refrig 33: 1029-1060.

\footnotetext{
How to cite

PEIXER GF, DUtRA SL, CALOMENO RS, SÁ NM, LANG GB, LOZANO AJ \& BARBOSA JR JR. 2022. Influence of Heat Exchanger Design on the Thermal Performance of a Domestic Wine Cooler Driven by a Magnetic Refrigeration System. An Acad Bras Cienc 94: e20200563. DOI 10.1590/0001-3765202220200563.
}

Manuscript received on April 15, 2020; accepted for publication on October 26, 2020 


\section{GUILHERME F. PEIXER}

https://orcid.org/0000-0002-5238-4910

SERGIO L. DUTRA

https://orcid.org/0000-0002-1933-5797

RICARDO S. CALOMENO

https://orcid.org/0000-0001-7916-2747

NATÁLIA M. DE SÁ

https://orcid.org/0000-0002-5584-6279

GUSTTAV B. LANG

https://orcid.org/0000-0002-9033-341X

JAIME A. LOZANO

https://orcid.org/0000-0003-2682-9952

\section{JADER R. BARBOSA JR}

https://orcid.org/0000-0002-8753-6670

Universidade Federal de Santa Catarina, Departamento de Engenharia Mecânica, Laboratórios de Pesquisa em Refrigeração e Termofísica (POLO), Campus Trindade, Rua Roberto Sampaio Gonzaga, s/n, Trindade, 88040-900 Florianópolis, SC, Brazil

Correspondence to: Jader R. Barbosa Jr

E-mail:jrb@polo.ufsc.br

\section{Author contributions}

JAL and JRB obtained funding for the research. GFP, SLD, GBL, RSC, JAL and JRB developed the theoretical formalism. GBL and GFP implemented the model and performed the simulations. SLD, NMS, GFP and JAL conceived, planned and executed the experiments. GFP, SLD, NMS, RSC, GBL, JAL and JRB analyzed the data. GFP, JAL and JRB wrote the manuscript with input from all authors.

\section{(cc) BY}

